\title{
EFFECT OF THERMAL AND NON-THERMAL PROCESSING ON THE NUTRITIONAL COMPOSITION, PASTING PROFILE AND PROTEIN SECONDARY STRUCTURE OF ALFALFA
}

\author{
- Research paper - \\ Prashant SAHNI ${ }^{1}$, Savita SHARMA, Arashdeep SINGH, Gurkirat KAUR \\ Department of Food Science and Technology, Punjab Agricultural University, Ludhiana (Punjab), \\ India-141004
}

\begin{abstract}
Alfalfa is an unconventional alternative legume and its potentiality for utilization can be improved by processing. In this study, alfalfa seeds were processed by different thermal and non-thermal techniques and evaluated for their physical properties, colour characteristics, nutritional composition, pasting profile and protein secondary structure. The results were analyzed using Principal Component Analysis to elucidate the effect of processing. Colour of the flour was more affected by thermal processing in comparison to non-thermal processing. Nutritional composition of alfalfa flour was significantly affected by germination as compared to other methods and germinated flour showed an increase in the protein content. All the processing treatments resulted in improving the pasting properties except for germination. Particularly, marked improvement in the pasting properties was observed by wet heat processing and soaking. ATR-FTIR exhibited change in the secondary structure of the protein as a result of processing and showed the dominance of intermolecular $\beta$-sheets in extrusion, germination and microwave treated flour and formation of antiparallel $\beta$-sheets after dry heat processing. Wet heat processing and soaking treatment can be employed for alfalfa for enhancing its techno-functionality.
\end{abstract}

Keywords: alfalfa; ATR-FTIR; pasting; processing

\section{INTRODUCTION}

Lucerne or alfalfa (Medicago sativa L.) is an extensively cultivated ancient fodder crop. The ability of alfalfa to thrive scanty water conditions due to its good root system allows its cultivation in poorly irrigated lands (Pandey and Roy, 2011). Alfalfa seeds have high crude protein, essential fatty acids, vitamins and minerals (Giuberti et al., 2017; Sahni and Sharma, 2020). Alfalfa seeds also constitute a high amount of bioactive constituents viz. total phenols, flavonoids and saponins (Sahni and Sharma, 2020). Saponins of alfalfa seeds exhibit therapeutic potential due to high antioxidant activity, prevention of atherosclerosis and reduction of cholesterol (Khaleel et al., 2005; Mölgaard et al., 1987; Malinow, 1981). Alfalfa seeds exhibit good antioxidant properties in terms of free radical scavenging, metal chelating activity and ferric reduction power (Sahni and Sharma, 2020).

Legumes are consumed in a variety of ways by

Received: 13.01.2021

Accepted in revised form:30.04.2021 conventionally processing them by pressure cooking, sprouting and roasting; that not only improves the palatability of the legumes but also enhances their nutritive value by the reduction in the antinutrients and increase in the in vitro digestibility of the nutrients (Sahni et al., 2021; Segev et al., 2012). Besides processing the legumes by conventional methods of processing, alternative processing techniques like microwave processing and extrusion can be also be employed for enhancing the cooking quality of the legumes and improving their bioactive potential and technofunctional properties (Divekar et al, 2017; Sahni and Sharma, 2020; Sahni et al., 2021). Sahni and Sharma (2020) reported that the processing of alfalfa seeds resulted in decreasing their cooking time and antinutritional factors and enhancing their functional properties and bioactive potential.

Besides exerting its effect on the bioactive potential and techno-functionality, processing can modify the nutritional constituents of legumes depending on the method employed and the conditions of processing. For instance, germination is manifested with the alteration of nutritional

${ }^{1}$ Corresponding author. E-Mail address: ftech.sahni@gmail.com 
constituents due to depletion of nutrients in the endosperm as a result of sprout growth or due to remobilization of nutrients during the process of germination (Liptay and Arevalo, 2000). Similarly, soaking can also result in the alteration in the nutritional composition due to leaching loss and thermal processing can alter the composition by complexation of the macromolecules. Pasting property of food grains is important for their utilization in products where the pasting of flour is crucial for the final desirable texture of the food product. Processing of legumes has demonstrated alteration in their pasting property, where certain a processing method may have a positive or detrimental effect on the pasting of the legume flour (Kaur et al., 2015; Adegunwa et al., 2012).

Processing also results in changing the structural and morphological characteristics of the legumes and their resultant flour. These changes in the macromolecules are particularly advantageous in

\section{MATERIALS AND METHODS}

\section{Processing Treatments}

Clean and sound alfalfa seeds were subjected to different processing techniques. The processing conditions for different treatments were finalized after conducting preliminary trials. Seeds were subjected to thermal treatments viz. wet heating, microwave (MW) treatment, dry heating and extrusion processing. Soaking and germination were employed among non-thermal processing treatments.

\section{Thermal processing treatments \\ Wet Heating}

Wet heating was carried out by autoclaving alfalfa seeds at $110^{\circ} \mathrm{C}$ for $10 \mathrm{~min}$. Processed seeds were dried to the moisture content of $8 \%$ in a hot air oven.

\section{Microwave (MW) treatment}

MW treatment was carried out by adjusting the moisture content of alfalfa seeds to $25 \%$ prior to processing. Processing was carried out at 2450 $\mathrm{MHz}$ for $3 \mathrm{~min}$. Processed seeds were dried to $8 \%$ m.c in a hot air oven.

\section{Dry heating}

Alfalfa seeds were spread in a thin layer in metallic trays and heated at a temperature of $120^{\circ} \mathrm{C}$ for 20 min using hot air oven.

\section{Extrusion}

Extrusion was carried out in co-rotating intermeshing twin-screw extruder Clextral BC 21 (Clextral, Firminy, France) at $150{ }^{\circ} \mathrm{C}$ barrel temperature, $25 \%$ moisture content of feed and predicting the techno-functionality of processed legumes and legume flours (Del Socorro López Cortez et al., 2016). Different methods employed in observing these changes include X-ray diffraction (XRD), scanning electron microscopy (SEM) and Attenuated Total Reflectance-Fourier Transform Infrared Spectroscopy (ATR-FTIR). However, ATR-FTIR can be particularly an easy, non-destructive and quick technique to observe the processing induced changes in the legume flours and its manifestation with the change in the secondary structure of proteins (Kaur et al, 2020; Sahni et al. 2020). Therefore, the study was designed to process alfalfa seeds by different thermal and non-thermal processing techniques and evaluated the effect of processing on physical properties, colour characteristics, proximate composition, pasting characteristics and secondary structure of the protein.

screw speed of $150 \mathrm{rpm}$. Mass obtained after extrusion was dried to $8 \%$ m.c in a hot air oven.

\section{Non-Thermal processing treatments \\ Soaking}

Soaking of seeds was done at room temperature $\left(27 \pm 2^{\circ} \mathrm{C}\right)$ for $12 \mathrm{~h}$, keeping the seed to water ratio 1:10 (w/v). Steep water was discarded and soaked seeds were dried to $8 \%$ m.c in a hot air oven.

\section{Germination}

Germination was carried out by soaking seeds for 8 h, followed by germination at $28{ }^{\circ} \mathrm{C}$ and R.H. 90$95 \%$ for $48 \mathrm{~h}$ in an incubator. Germinated seeds were dried to the moisture content of $8 \%$ and manually devegetated.

\section{Preparation of the flour}

Alfalfa flour was obtained from unprocessed and processed seeds by milling in using cyclotec mill and milled flour was passed through 60 mesh sieve.

\section{Physical properties}

Bulk and tap density: Bulk density and tap density were assessed by the procedure of Singh et al. (2017) and Chegini and Ghobadian (2005) respectively and expressed as $\mathrm{g} / \mathrm{cm}^{3}$.

Flowbility and cohesiveness: Flowability and cohesiveness of the powder were expressed as Carr index (CI) and Hausner ratio (HR) respectively (Jinapong et al., 2008). CI and HR were calculated using the following equations:

$$
\begin{aligned}
& \mathrm{CI}=\frac{(\rho \text { tap density }-\rho \text { bulk density })}{\rho \text { tap density }} \\
& \mathrm{HR}=\rho \text { tap density } / \rho \text { bulk density }
\end{aligned}
$$




\section{Colour characteristics}

Flour colour characteristics were assessed using Hunter lab colorimeter (CR-300 Minolta Camera, Japan) in terms of $\mathrm{L}^{*}, \mathrm{a}^{*}$ and $\mathrm{b}^{*}$ values. Chroma $\left(C^{*}\right)$ and hue angle $\left(h^{\circ}\right)$ were calculated as follows: $\mathrm{C}^{*}=\sqrt{\mathrm{a}^{* 2}+\mathrm{b}^{* 2}}$

$\mathrm{h}^{\circ}=\tan ^{-1} \frac{\mathrm{a}^{* 2}}{\mathrm{~b}^{* 2}}$

\section{Nutritional composition}

Crude protein (using the factor $6.25 \times \mathrm{N}$ ), crude fat, crude fibre and ash were determined by AACC (2000). NFE was assessed by the difference method where the sum of crude protein, crude fat, crude fibre and ash was subtracted from 100. Values were expressed on dry matter basis.

\section{Pasting profile}

Pasting profile was studied by the procedure documented by Sahni et al. (2019) using Rapid Visco Analyzer (RVA), model Starch Master (Newport Scientific, Australia) and expressed in terms of peak viscosity, hold viscosity, final

\section{RESULTS AND DISCUSSION}

\section{Physicochemical characteristics}

Increased bulk and tap density of alfalfa flour were manifested with all processing treatments except for germination which showed a reduction in the bulk and tap density (Table 1). Reduced bulk density of germinated alfalfa flour will allow its usage in weaning and geriatric foods (Elkhalifa and Bernhardt, 2010). Similar reduction in the bulk density of flour was observed after the germination of sorghum and brown rice (Elkhalifa and Bernhardt, 2010; Singh et al., 2017). However, a particularly higher value of bulk density for dry heating and extrusion processed flour can be ascribed to the shrinking of cellular structure and excessive shearing of flour particles during dry heating and extrusion processing respectively, that resulted in less porous flour particles on milling (Sahni and Sharma, 2020). Reduction in the bulk density after germination can be attributed to the weakening of the cellular structure and degradation of the starch and protein molecules to low weight monomers that resulted in the formation of rough and porous flour particles that exhibited low bulk density. Based on the Carr Index and Hausner's Ratio, microwave treatment and soaking exerted a detrimental effect on the flowability of the flour and the flours exhibited poor flowability. High cohesiveness was also manifested with the soaked and microwave processed flours, whereas other viscosity, breakdown viscosity and setback viscosity.

\section{Attenuated total reflectance Fourier transform infrared spectroscopy (ATR-FTIR)}

Spectral characteristics of the flours were evaluated as per Sahni et al. (2020) using Fourier transform infrared spectrometer (Thermo Scientific, Nicolet 67000) in the range 400-4000 $\mathrm{cm}^{-1}$ to determine the effect of processing on the secondary structure of the protein.

\section{Statistical analysis}

Five replications were taken for physical and colour characteristics whereas the rest of the analysis were carried out in triplicate. The data is subjected to analysis by ANOVA followed by post-hoc Tukey's test using SPSS software (Version 22.0, IBM Corporation) at $\mathrm{p}$-value $<0.05$ as significant. Physical, colour, nutritional and pasting characteristics of alfalfa flours were subjected to Principal Component Analysis (Statistica v.12).

flour samples exhibited fair flowability and intermediate cohesiveness.

The colour values indicate that processing exerted a significant effect on the colour characteristics of the processed flours. The drastic change in $L^{*}, a^{*}$ and $b^{*}$ values were particularly observed in the case of extrusion treatment with a marked decrease in $L^{*}$ value (59.55) and increase in $a^{*}$ value $(0.21)$. The consequent increase was reflected in the hue value of flour (1.54), where extrusion processed flour exhibited positive hue values in contrast to other flours. An increase in the redness $\left(a^{*}\right)$ was also observed after microwave processing. Colour change was more evident after microwave processing and extrusion due to the formation of maillard reaction products during the processing (Fernandes et al., 2003).

Germination exhibited pronounced effect on the proximate composition of the alfalfa seeds in contrast to other processing treatments (Table 2). Germination resulted in increasing the protein content and decreasing the crude fat, crude fibre and ash content. The aforesaid changes in the proximate composition of the germinated seeds can be attributed to the activity of the hydrolytic enzymes that degrade the seed coat whereas the endosperm of the seed was utilized as an energy reserve for the growth of the embryo (Singh et al., 2017). The reduction in the extractable fat was due to the breakdown of the fats to fatty acid and their subsequent oxidation and utilization in the various 
biochemical processes during the germination of the seed (Jan et al., 2016). The decrease in the ash content during soaking and germination can be attributed to the loss of minerals during their soaking in the steep water. The reduction in dry matter due to loss of lipid, crude fibre, ash and carbohydrates resulted in the overall increase in the protein content. Furthermore, during the germination, the decrease in the ash content can be due to the remobilization of minerals (Liptay and Arevalo, 2000). Pandey et al. (2019) also reported an increase in protein content and decrease in crude fat, crude fibre and ash in malted alfalfa seeds. A slight increase in the crude fibre was observed after extrusion, which can be attributed to the development of resistant starch due to the complexation of some starch with lipid and protein (Sahni and Sharma, 2020; Kamau et al., 2020).

\section{Pasting profile}

Rheological properties of the flour are crucial for the development of the food products and supplementation of unconventional ingredients tends to alter the rheological properties of the resultant dough (Ognean \& Danciu, 2009; Ognean et al., 2009; Ognean et al., 2010; Vizitiu \& Danciu, 2011). Furthermore, the evaluation of rheological properties by instruments like Farinograph, Mixograph and Rapid Visco Analyzer helps in the characterization of flours for their intended use in the food product development (Vizitiu \& Danciu, 2011; Iancu \& Haubelt, 2011; Sahni et al., 2019). Flours obtained from the alfalfa seeds processed by different processing techniques exhibited wide variation in their pasting profile (Table 3). Pasting property is a predominant function of starch in food grains. Therefore, cereal grains often exhibit superior pasting properties in comparison to legumes (Alcázar-Alay and Meireles, 2015). It is well evident from Table 3 that alfalfa flour exhibited very low values for peak, hold and breakdown viscosity in comparison to final viscosity (FV). Peak viscosity (PV) is a maximum viscosity attained when flour slurry is heated. The peak viscosity is caused by the leaching of amylose from the swollen starch granules that increases the viscosity of the suspension. Therefore, the peak viscosity of the flour slurry can be correlated with the ease of disintegration of the starch granule with consequent leaching of the amylose. However, the low value for peak viscosity $(11 \mathrm{cP})$ in alfalfa can be attributed to the presence of resistant starch that takes longer time to disintegrate and showed lower leaching of amylose and consequently reduced peak viscosity (Giuberti et al., 2018). Reddy et al. (2015) also reported the marked reduction in the peak viscosity with the increase in the resistant starch content in the sample.

However, the hold viscosity value of alfalfa flour was $10 \mathrm{cP}$ with a consequently lower value for the breakdown viscosity $(1 \mathrm{cP})$ representing the less disintegration and shear thinning of the flour. Usually, the final viscosity of starch/cereal flour paste is a virtue of re-association of amylose chains. However, pronouncedly higher values of final viscosity $(267.33 \mathrm{cP})$ in comparison to peak viscosity speculate the manifestation of final viscosity with a higher degree of re-association between the starch and protein molecules.

The marked increase in the PV $(230 \mathrm{cP})$ after wet heating can be ascribed to the partial denaturation of the protein as well as partial gelatinization of the starch (Sahni and Sharma, 2020; Sahni et al., 2018). Furthermore, high hold viscosity and low breakdown viscosity was observed in the flour obtained after wet heating treatment. FV also increased $(587 \mathrm{cP})$ after wet heat processing due to partial denaturation of protein that tends to associate better with the starch chains and resulted in the higher FV. In contrast to wet heat processed flour, the microwave treated flour showed less increase in the PV $(55 \mathrm{cP})$. The increase in the PV of microwave treated flour can be attributed to the increase in the crystallinity of starch due to microwave induced annealing of the starch (Jacobs et al., 1995; Zhong et al., 2020). Furthermore, FV of the microwave treated flour was lower in comparison to flour processed by wet heat processing. Dry heat processed flour showed zero value for the PV. Application of high temperature for a longer duration $\left(120^{\circ} \mathrm{C}\right.$ for 20 mins $)$ might have resulted in the disruption of glycosidic bonds between the starch monomers and resulted in the dextrinization of the starch that consequently caused the absence of pasting ( $\mathrm{Li}$ et al., 2013; Lee et al., 2017). However, the final viscosity of $228.33 \mathrm{cP}$ can be attributed to the gelation of the denatured proteins (Sahni et al., 2018). Extrusion processing also improved the $\mathrm{PV}$ due to the fragmentation of macromolecules that resulted in the easy ingress of moisture and leaching of the amylose. However, comparatively lower PV in comparison to wet heat processing can be attributed to complexation of some starch with lipid and protein and thereby reducing its swelling (Sahni and Sharma, 2020; Kamau et al., 2020).

In the non-thermal processing, soaking markedly improved the pasting properties of the alfalfa flour contrary to germination that exhibited a detrimental effect on the pasting characteristics. Furthermore, among all the processing techniques, soaking treatment showed the highest increase in 
the PV, HV and FV. Kaur et al. (2015) observed a similar pronounced increase in pasting viscosities in the mung after soaking treatment. High peak viscosity after soaking treatment can be due to the reduction in the binding forces between protein and starch molecules that rendered higher ingress of water for better swelling (Sahni and Sharma, 2020; Buckman et al., 2018). Lowest values for $\mathrm{PV}, \mathrm{HV}$ and FV were observed in the germinated alfalfa flour. The aforesaid trend for PV can be attributed to the degradation of starch to sugar during the process of germination. Furthermore, the negative values for $\mathrm{HV}$ and FV depicted the shear thinning of the flour slurry during heating and even after cooling down. In addition, the negative value of FV also indicated the absence of association of starch molecules among themselves and also with the proteins, since germination causes degradation of the polymeric structure of starch molecules. Similar negative values for the $\mathrm{HV}$ and FV were reported for the microalgae meal (Sahni et al., 2019). Shafie et al. (2016) and Ascheri et al. (2012) reported negative values for the breakdown viscosity for Seratus rice cultivar and pregelatinized red rice flour respectively. Sofi et al. (2020) also reported the reduction in the values of pasting properties of germinated chickpea flours in comparison to ungerminated counterpart. Overall, the pasting profile elucidated that unprocessed alfalfa flour does not have good pasting properties. However, the pasting profile of alfalfa can be improved by wet heat processing and soaking among thermal and non-thermal processing techniques respectively.

\section{Spectral Characteristics}

The ATR-FTIR spectra can be used for the identification of the different functional groups present that are manifested with the particular constituents present in the alfalfa flour. For instance, the presence of phenols and saponins corresponds to 3200 and $2970 \mathrm{~cm}^{-1}$ respectively (Figure 1). Furthermore, spectral characteristics of flours can be of great importance to predict the changes in the conformation of protein as a result of processing by evaluation of peaks in the amide I $(\mathrm{C}=\mathrm{O}$ stretching) and amide II $(\mathrm{N}-\mathrm{H}$ bending and C-N stretching) regions of the ATR-FTIR spectra (Sahni et al., 2020). Amide I and amide II region corresponds to $1600-1700 \mathrm{~cm}^{-1}$ and $1580-1480 \mathrm{~cm}^{-}$

${ }^{1}$ (Kong and $\mathrm{Yu}, 2007$ ). Particularly, amide $\mathrm{I}$ is more sensitive region to elucidate the changes associated with the secondary structure of the protein due to its association with the backbone of the protein molecule and allows monitoring of the dynamics of protein conformation as a result of processing (Usoltsev et al., 2019). The shift in the peaks was observed in the amide I region where unprocessed and wet heat processed flour showed peaks at 1649.1 and $1649.0 \mathrm{~cm}^{-1}$ respectively. These peaks are manifested with the presence of $\alpha$ helix. Soaking resulted in the shift of peak at $1647.0 \mathrm{~cm}^{-1}$ and can be manifested with the unordered structure of the protein. However, the gradual shift in the peak to $1636.8,1635.6$ and $1635.4 \mathrm{~cm}^{-1}$ in extrusion, germination and microwave treated flour respectively exhibited the dominance of intermolecular $\beta$-sheets as a result of denaturation (Usoltsev et al., 2019). Conformational changes in the protein of processed flours can be further manifested with the enhancement in the functional properties of alfalfa flour as reported by Sahni and Sharma (2020). Flour processed by dry heat treatment showed peak at $1674.4 \mathrm{~cm}^{-1}$ and can be manifested with the formation of anti-parallel $\beta$-sheets as a result of excessive thermal denaturation, which can be due to the application of high temperature for a longer duration $\left(120^{\circ} \mathrm{C}\right.$ for $\left.20 \mathrm{mins}\right)$. This finding can be correlated with the poor freeze-thaw stability of the dry heat treated alfalfa flour as reported by Sahni and Sharma (2020).

\section{Principle Component Analysis (PCA)}

Principle Component Analysis of alfalfa flours obtained after different processing treatments is shown in the loading (Figure 2A) and score plot (Figure 2B). The properties that lie in the same quadrant of loading plot are positively correlated whereas the properties that lie in the opposite quadrants are negatively correlated. Similarly, the samples that lie close to each other on the score plot represent similarity in the characteristics whereas the samples that lie far from each other show variations in their characteristics. It is evident from the loading plot that hold viscosity (HV) and breakdown viscosity (BV) are negatively correlated and this effect can be particularly observed in the germinated flour $(\mathrm{G})$ which is manifested with high BV. Furthermore, PV and $\mathrm{BV}$ are positively correlated with the NFE that also constitutes starch. Among different samples, the germinated sample showed wide variations from the rest of the samples particularly attributing to its variation in the proximate composition and pasting profile. 
Table 1. Effect of thermal and non-thermal processing treatments on physical and colour characteristics

\begin{tabular}{|c|c|c|c|c|c|c|c|}
\hline & \multirow{2}{*}{ Unprocessed } & \multicolumn{4}{|c|}{ Thermal Processing Treatments } & \multicolumn{2}{|c|}{$\begin{array}{c}\text { Non-Thermal Processing } \\
\text { Treatments } \\
\end{array}$} \\
\hline & & Wet Heating & MW Treatment & Dry Heating & Extrusion & Soaking & Germination \\
\hline \multicolumn{8}{|c|}{ Physical Characteristics } \\
\hline Bulk Density $\left(\mathrm{g} / \mathrm{cm}^{3}\right)$ & $0.427 \pm 0.0^{\mathrm{e}}$ & $0.455 \pm 0.0^{\mathrm{d}}$ & $0.446 \pm 0.0^{\mathrm{c}}$ & $0.521 \pm 0.0^{\mathrm{a}}$ & $0.507 \pm 0.0^{\mathrm{b}}$ & $0.430 \pm 0.0^{\mathrm{e}}$ & $0.398 \pm 0.0^{\mathrm{f}}$ \\
\hline Tap Density $\left(\mathrm{g} / \mathrm{cm}^{3}\right)$ & $0.598 \pm 0.0^{\mathrm{f}}$ & $0.674 \pm 0.0^{\mathrm{e}}$ & $0.732 \pm 0.0^{\mathrm{a}}$ & $0.700 \pm 0.0^{\mathrm{b}}$ & $0.695 \pm 0.0^{c}$ & $0.683 \pm 0.0^{\mathrm{d}}$ & $0.613 \pm 0.0^{\mathrm{f}}$ \\
\hline Carr Index $(\%)$ & $28.53 \pm 0.09^{f}$ & $32.39 \pm 0.16^{\mathrm{c}}$ & $39.17 \pm 0.11^{\mathrm{a}}$ & $25.47 \pm 0.22^{\mathrm{g}}$ & $27.25 \pm 0.17^{\mathrm{f}}$ & $37.11 \pm 0.12^{b}$ & $31.27 \pm 0.11^{\mathrm{d}}$ \\
\hline Flowability & Fair & Fair & Bad & Fair & Fair & Bad & Fair \\
\hline Hausner's ratio & $1.40 \pm 0.01^{\mathrm{e}}$ & $1.48 \pm 0.01^{\mathrm{c}}$ & $1.64 \pm 0.01^{\mathrm{a}}$ & $1.34 \pm 0.02^{\mathrm{f}}$ & $1.37 \pm 0.01^{\mathrm{f}}$ & $1.58 \pm 0.01^{\mathrm{b}}$ & $1.45 \pm 0.0^{\mathrm{d}}$ \\
\hline Cohesiveness & Intermediate & High & High & Intermediate & Intermediate & High & High \\
\hline \multicolumn{8}{|l|}{ Colour Values } \\
\hline $\mathrm{L}^{*}$ & $76.80 \pm 0.45^{\mathrm{a}}$ & $76.20 \pm 0.38^{\mathrm{a}}$ & $75.28 \pm 0.59^{a}$ & $76.27 \pm 0.66^{\mathrm{a}}$ & $59.55 \pm 0.58^{\mathrm{d}}$ & $73.71 \pm 0.43^{b}$ & $71.49 \pm 0.13^{c}$ \\
\hline$a^{*}$ & $-3.42 \pm 0.13^{c}$ & $-3.51 \pm 0.10^{c}$ & $-2.32 \pm 0.11^{\mathrm{b}}$ & $-3.39 \pm 0.09^{c}$ & $0.21 \pm 0.03^{\mathrm{a}}$ & $-3.41 \pm 0.14^{c}$ & $-2.07 \pm 0.05^{\mathrm{b}}$ \\
\hline$b^{*}$ & $21.76 \pm 0.13^{b}$ & $21.14 \pm 0.11^{\mathrm{c}}$ & $21.34 \pm 0.23^{\mathrm{c}}$ & $21.28 \pm 0.21^{\mathrm{c}}$ & $21.70 \pm 0.05^{\mathrm{b}}$ & $18.22 \pm 0.33^{\mathrm{d}}$ & $26.38 \pm 0.07^{a}$ \\
\hline Chroma & $22.12 \pm 0.11^{\mathrm{b}}$ & $21.36 \pm 0.14^{\mathrm{b}}$ & $21.33 \pm 0.31^{\mathrm{b}}$ & $21.44 \pm 0.42^{\mathrm{ab}}$ & $21.65 \pm 0.12^{\mathrm{b}}$ & $18.24 \pm 0.24^{\mathrm{a}}$ & $26.59 \pm 0.09^{a}$ \\
\hline Hue & $-1.41 \pm 0.01^{\mathrm{c}}$ & $-1.41 \pm 0.01^{\mathrm{c}}$ & $-1.45 \pm 0.01^{\mathrm{d}}$ & $-1.39 \pm 0.02^{\mathrm{b}}$ & $1.54 \pm 0.01^{\mathrm{a}}$ & $-1.39 \pm 0.01^{\mathrm{b}}$ & $-1.49 \pm 0.0^{\mathrm{e}}$ \\
\hline
\end{tabular}

Values are expressed as mean \pm standard deviation $(n=5)$. The means within row followed by different superscripts are significantly different at $\mathrm{p}<0.05$ 
Table 2. Effect of thermal and non-thermal processing treatments on proximate composition

\begin{tabular}{|c|c|c|c|c|c|c|c|}
\hline & \multirow[b]{2}{*}{ Unprocessed } & \multicolumn{4}{|c|}{ Thermal Processing Treatments } & \multicolumn{2}{|c|}{ Non-Thermal Processing Treatments } \\
\hline & & Wet Heating & MW Treatment & Dry Heating & Extrusion & Soaking & Germination \\
\hline Crude Protein $(\%)$ & $34.58 \pm 0.89^{\mathrm{a}}$ & $34.78 \pm 1.03^{\mathrm{a}}$ & $34.28 \pm 0.78^{\mathrm{a}}$ & $34.98 \pm 1.09^{\mathrm{a}}$ & $35.09 \pm 1.12^{\mathrm{a}}$ & $33.94 \pm 0.84^{\mathrm{a}}$ & $39.45 \pm 0.52^{\mathrm{b}}$ \\
\hline Crude Fat $(\%)$ & $7.13 \pm 0.19^{\mathrm{a}}$ & $6.94 \pm 0.23^{\mathrm{a}}$ & $7.05 \pm 0.29^{\mathrm{a}}$ & $6.85 \pm 0.21^{\mathrm{a}}$ & $7.12 \pm 0.12^{\mathrm{a}}$ & $7.11 \pm 0.23^{\mathrm{a}}$ & $4.67 \pm 0.12^{\mathrm{b}}$ \\
\hline Crude Fibre (\%) & $6.24 \pm 0.12^{\mathrm{b}}$ & $6.26 \pm 0.21^{\mathrm{b}}$ & $6.12 \pm 0.24^{b}$ & $6.44 \pm 0.23^{b}$ & $7.14 \pm 0.14^{\mathrm{a}}$ & $6.15 \pm 0.11^{\mathrm{b}}$ & $5.02 \pm 0.09^{c}$ \\
\hline $\operatorname{Ash}(\%)$ & $4.28 \pm 0.08^{\mathrm{a}}$ & $4.34 \pm 0.07^{\mathrm{a}}$ & $4.23 \pm 0.10^{\mathrm{a}}$ & $4.34 \pm 0.05^{\mathrm{a}}$ & $4.36 \pm 0.04^{\mathrm{a}}$ & $3.89 \pm 0.05^{\mathrm{b}}$ & $4.01 \pm 0.04^{\mathrm{b}}$ \\
\hline $\operatorname{NFE}(\%)^{\circ}$ & 47.79 & 47.68 & 48.32 & 47.39 & 46.29 & 48.91 & 46.85 \\
\hline
\end{tabular}

Values are expressed on $\%$ dry weight basis as mean \pm standard deviation $(n=3)$.

${ }^{\circ}$ Nitrogen Free Extract: 100 - \% (Moisture + crude protein + crude lipid + crude fibre + ash)

The means within row followed by different superscripts are significantly different at $\mathrm{p}<0.05$

Table 3. Effect of thermal and non-thermal processing treatments on pasting profile

Thermal Processing Treatments

Non-Thermal Processing Treatments

\begin{tabular}{|c|c|c|c|c|c|c|c|}
\hline & Unprocessed & Wet Heating & MW Treatment & Dry Heating & Extrusion & Soaking & Germination \\
\hline Peak Viscosity (cP) & $11 \pm 0.0^{\mathrm{e}}$ & $230 \pm 3.60^{b}$ & $55 \pm 0.0^{\mathrm{d}}$ & $0 \pm 0.0^{\mathrm{f}}$ & $103.33 \pm 1.15^{\mathrm{c}}$ & $283 \pm 2.0^{\mathrm{a}}$ & $0 \pm 0.0^{\mathrm{f}}$ \\
\hline Hold Viscosity (cP) & $10 \pm 0.0^{\mathrm{e}}$ & $219.33 \pm 2.30^{\mathrm{b}}$ & $53 \pm 2.0^{\mathrm{d}}$ & $0 \pm 0.0^{\mathrm{f}}$ & $97.33 \pm 1.15^{\mathrm{c}}$ & $277 \pm 1.0^{\mathrm{a}}$ & $-48577 \pm 0.0^{g}$ \\
\hline Final Viscosity (cP) & $277.33 \pm 2.08^{\mathrm{e}}$ & $587 \pm 1.73^{\mathrm{b}}$ & $328 \pm 0.0^{\mathrm{d}}$ & $228.33 \pm 2.51^{\mathrm{f}}$ & $385.66 \pm 1.52^{c}$ & $632.33 \pm 3.21^{\mathrm{a}}$ & $-110 \pm 0.0^{\mathrm{g}}$ \\
\hline Breakdown Viscosity (cP) & $1 \pm 0.0^{\mathrm{d}}$ & $10.66 \pm 2.51^{\mathrm{b}}$ & $2.66 \pm 1.15^{\mathrm{f}}$ & $0 \pm 0.0^{\mathrm{e}}$ & $6.33 \pm 1.15^{\mathrm{c}}$ & $6.33 \pm 1.15^{\mathrm{c}}$ & $48577 \pm 0.0^{\mathrm{a}}$ \\
\hline Setback Viscosity (cP) & $267.33 \pm 2.08^{\mathrm{e}}$ & $367.66 \pm 2.08^{b}$ & $266.33 \pm 1.15^{\mathrm{e}}$ & $228.33 \pm 2.51^{\mathrm{f}}$ & $288.33 \pm 2.08^{\mathrm{d}}$ & $355.66 \pm 2.08^{c}$ & $48467 \pm 0.0^{\mathrm{a}}$ \\
\hline
\end{tabular}

Values are expressed as mean \pm standard deviation $(n=3)$. The means within row followed by different superscripts are significantly different at $\mathrm{p}<0.05$ 


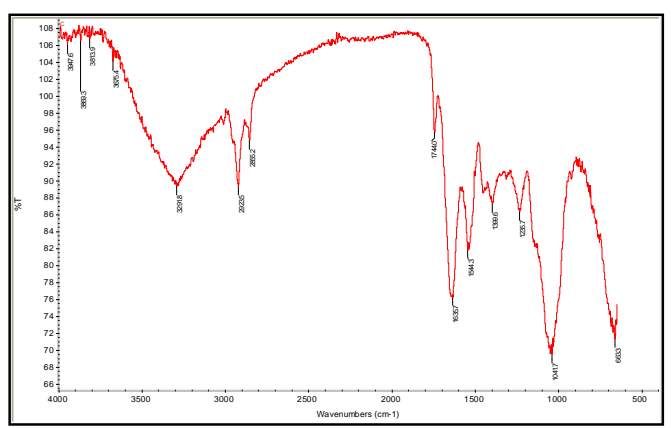

Unprocessed

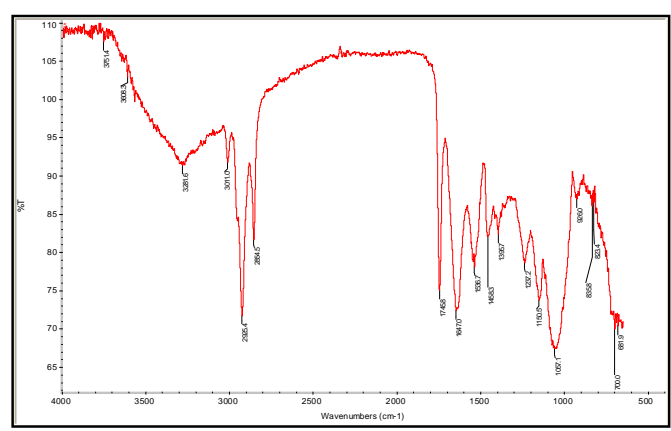

MW Treatment

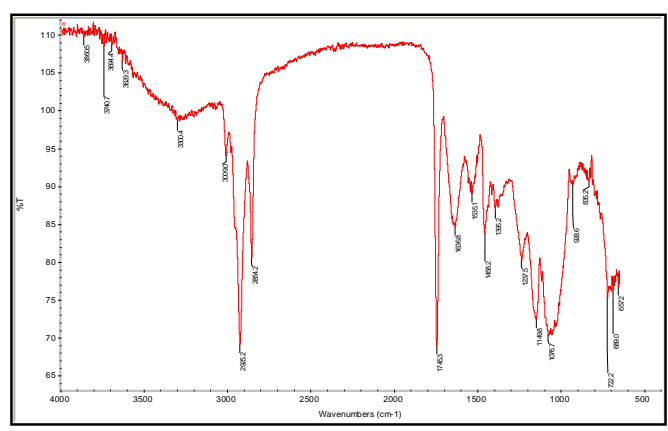

Extrusion

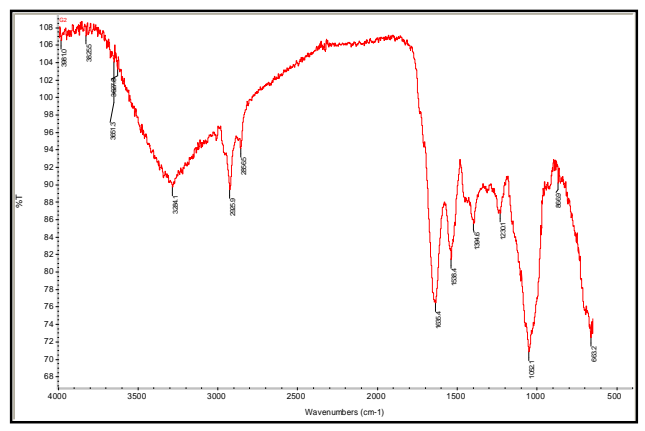

Germination

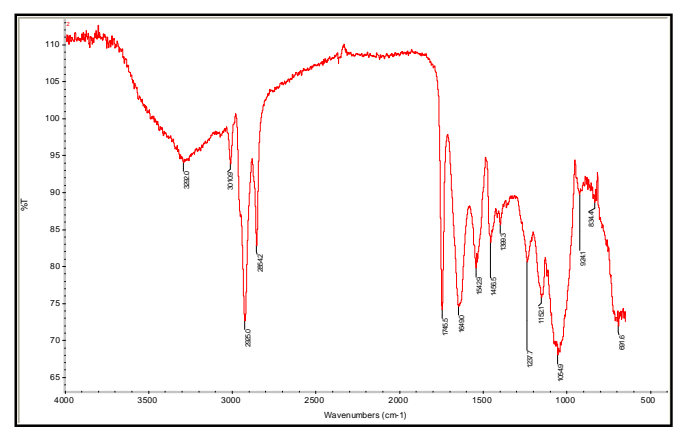

Wet Heating

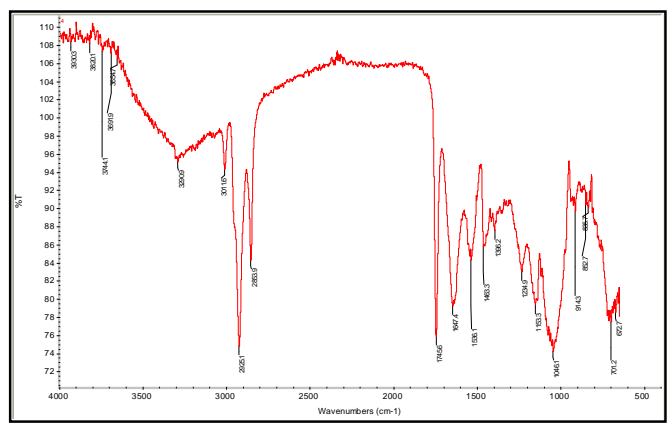

Dry Heating

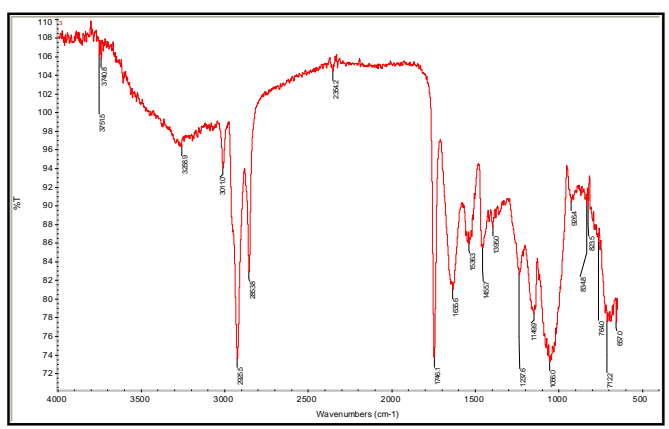

Soaking

Figure 1. Spectral characteristics of unprocessed and processed alfalfa flours 


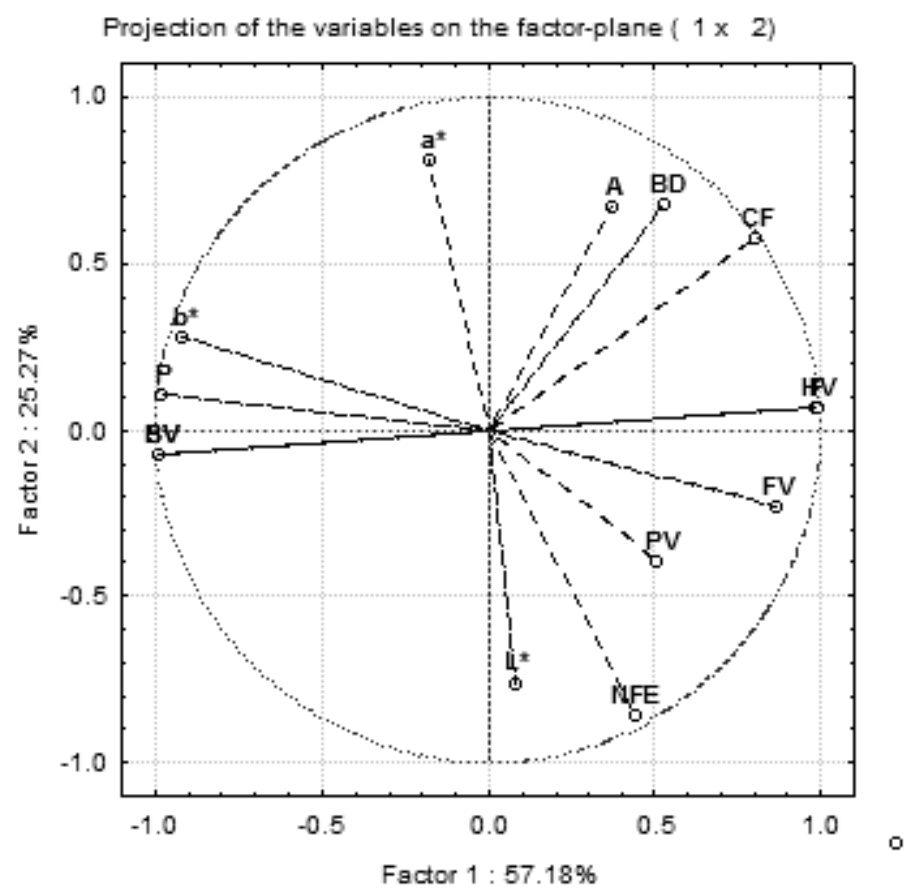

A

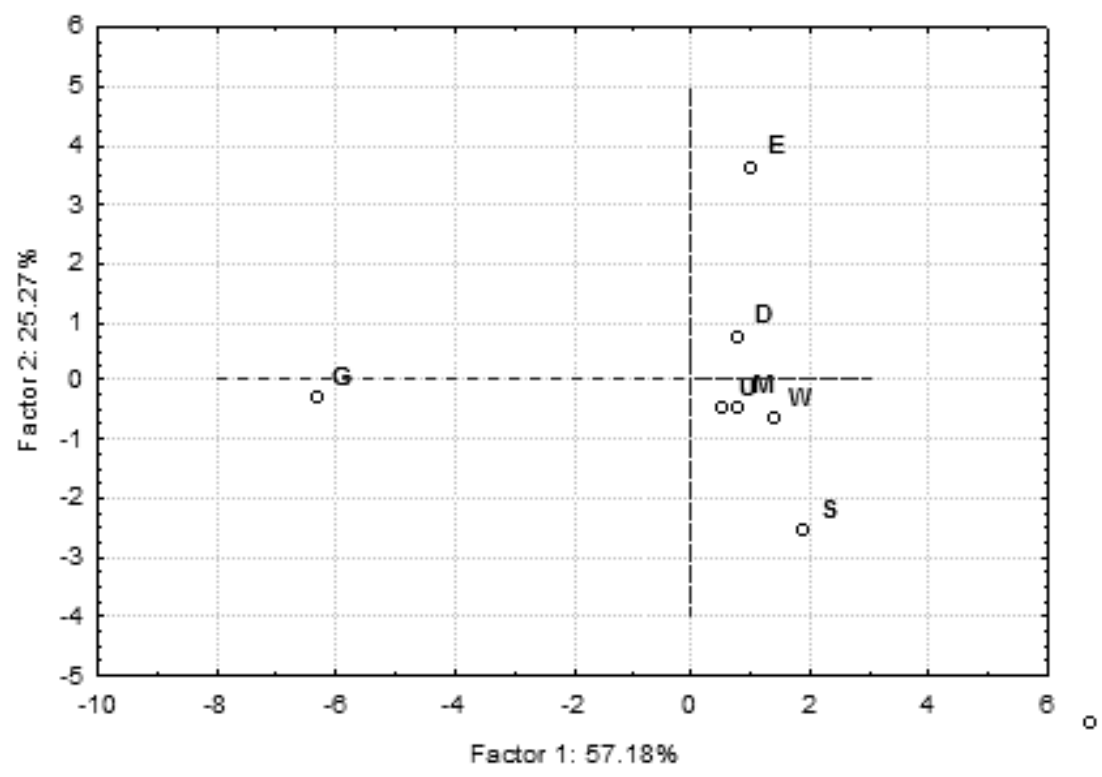

B

Figure 2. Principle Component Analysis (PCA) showing loading (A) and score (B) plot for alfalfa processed by different thermal and non-thermal processing methods. BD: Bulk density, $\mathrm{L}^{*}, \mathrm{a}^{*}, \mathrm{~b}^{*}$ (Colour values), P: Crude protein, F: Crude fat, CF: Crude fibre, A: Ash, NFE: Nitrogen free extract, PV: Peak viscosity, HV: Hold viscosity, FV: Final viscosity, BV: Breakdown viscosity, SV: Setback viscosity, U: Unprocessed; W: Wet Heating: M: Microwave Treatment; D: Dry Heating, E: Extrusion, S: Soaking, G: Germination 


\section{CONCLUSION}

Processing exhibited pronounced effect on the composition, pasting profile and secondary structure of the alfalfa flour. Among different thermal and non-thermal processing treatments, wet heat and soaking can be used respectively for improving the pasting properties of alfalfa flour for enhancing their techno-functionality in food products where good pasting properties are essential. ATR-FTIR spectra elucidated alteration in the secondary structure of protein after processing and showed the manifestation of conformational changes in the protein due to thermal denaturation.

\section{ACKNOWLEDGMENTS}

Prashant Sahni is thankful to the Department of Science and Technology, India for the award of INSPIRE Fellowship (Sanction Order No. IF170737).

\section{REFERENCES}

1. A.A.C.C. (2000), Approved Methods of the American Association of Cereal Chemists, $10^{\text {th }}$ Ed.

2. Adegunwa, M. O., Bakare, H. A., Alamu, E. O., \& Abiodun, O. K. (2012). Processing effects on chemical, functional and pasting properties of cowpea flour from different varieties. Nigerian Food Journal, 30(1), 67-73.

3. Alcázar-Alay, S. C., \& Meireles, M. A. A. (2015). Physicochemical properties, modifications and applications of starches from different botanical sources. Food Science and Technology, 35(2), 215236.

4. Ascheri, D. P. R., Boêno, J. A., Bassinello, P. Z., \& Ascheri, J. L. R. (2012). Correlation between grain nutritional content and pasting properties of pre-gelatinized red rice flour. Revista Ceres, 59(1), $16-24$

5. Buckman, E. S., Oduro, I., Plahar, W. A., \& Tortoe, C. (2018). Determination of the chemical and functional properties of yam bean (Pachyrhizus erosus (L.) Urban) flour for food systems. Food science \& nutrition, 6(2), 457-463.

6. Chegini, G. R., \& Ghobadian, B. (2005). Effect of spray-drying conditions on physical properties of orange juice powder. Drying technology, 23(3), 657-668.

7. Del Socorro López Cortez, M., Rosales Martínez, P., Arellano Cárdenas, S., \& Cornejo Mazón, M. (2016). Antioxidants properties and effect of processing methods on bioactive compounds of legumes. In: Goyal AK (Ed.) Grain Legumes. (InTech, Croatia), pp.103-126.

8. Elkhalifa, A. E. O., \& Bernhardt, R. (2010). Influence of grain germination on functional properties of sorghum flour. Food Chemistry, 121(2), 387-392.

9. Fernandes, M. S., Wang, S. H., Ascheri, J. L. R., Oliveira, M. F., \& Costa, S. A. (2003). Effect of extrusion temperature in water absorption, solubility and dispersibility of pre-cooked corn-soybean (70: 30) flours. Food Science and Technology, 23(2), 234-239.

10. Giuberti, G., Rocchetti, G., Sigolo, S., Fortunati, P., Lucini, L., \& Gallo, A. (2018). Exploitation of alfalfa seed (Medicago sativa L.) flour into gluten-free rice cookies: Nutritional, antioxidant and quality characteristics. Food chemistry, 239, 679-687.

11. Iancu, M. L., \& Haubelt, G. (2011). Rheological behavior of dough with added potato (varieties Laura and Impala) in presence of $\mathrm{NaCl}$ and Saccharomyces cerevisiae. Acta Universitatis Cinbinesis, Series E: Food Technology, 15(1),17-29.

12. Jacobs, H., Eerlingen, R. C., Clauwaert, W., \& Delcour, J. A. (1995). Influence of annealing on the pasting properties of starches from varying botanical sources. Cereal chemistry 72(5):480-487.

13. Jan, R., Saxena, D. C., \& Singh, S. (2016). Physico-chemical, textural, sensory and antioxidant characteristics of gluten-Free cookies made from raw and germinated Chenopodium (Chenopodium album) flour. LWT-Food Science and Technology, 71, 281-287.

14. Jinapong, N., Suphantharika, M., \& Jamnong, P. (2008). Production of instant soymilk powders by ultrafiltration, spray drying and fluidized bed agglomeration. Journal of Food Engineering, 84(2), 194-205.

15. Kaur, D., Dhawan, K., Rasane, P., Singh, J., Kaur, S., Gurumayum, S., ... \& Kumar, V. (2020). Effect of different pre-treatments on antinutrients and antioxidants of rice bean (Vigna umbellata). Acta Universitatis Cinbinesis, Series E: Food Technology, 24(1), 25-38. 
16. Kaur, M., Sandhu, K. S., Ahlawat, R., \& Sharma, S. (2015). In vitro starch digestibility, pasting and textural properties of mung bean: effect of different processing methods. Journal of food science and technology, 52(3), 1642-1648.

17. Khaleel, A. E., Gad, M. Z., El-Maraghy, S. A., Hifnawy, M. S., \& Abdel-Sattar, E. (2005). Study of hypocholesterolemic and antiatherosclerotic properties of Medicago sativa L. cultivated in Egypt. Journal of Food \& Drug Analysis, 13(3), 212.

18. Kong, J., \& Yu, S. (2007). Fourier transform infrared spectroscopic analysis of protein secondary structures. Acta biochimica et biophysica Sinica, 39(8), 549-559.

19. Lee, S. J., Yang, Y. J., Chung, H. J., \& Lim, S. T. (2017). Effect of dry heating on physicochemical properties of pregelatinized rice starch. Cereal Chemistry, 94(6), 928-933.

20. Li, Y., Zhang, H., Shoemaker, C. F., Xu, Z., Zhu, S., \& Zhong, F. (2013). Effect of dry heat treatment with xanthan on waxy rice starch. Carbohydrate polymers, 92(2), 1647-1652.

21. Liptay, A., \& Arevalo, A. E. (2000). Plant mineral accumulation, use and transport during the life cycle of plants: a review. Canadian journal of plant science, 80(1), 29-38.

22. Malinow, M. R., McNulty, W. P., McLaughlin, P., Stafford, C., Burns, A. K., Livingston, A. L., \& Kohler, G. O. (1981). The toxicity of alfalfa saponins in rats. Food and cosmetics toxicology, 19, 443-445.

23. Mölgaard, J., Von Schenck, H., \& Olsson, A. G. (1987). Alfalfa seeds lower low density lipoprotein cholesterol and apolipoprotein B concentrations in patients with type II hyperlipoproteinemia. Atherosclerosis, 65(1-2), 173-179.

24. Ognean, M., \& Danciu, I. (2009). Research on the factors with implications on rheological properties of doughs. Acta Universitatis Cibiniensis Series E: Food Technology, 13(2), 41-48.

25. Ognean, M., Ognean, C. F., \& Danciu, I. (2009). Farinographic effects of several commercial xylanases on low extraction wheat flour. Acta Universitatis Cibiniensis Series E: Food Technology, 13(2), 25-34.

26. Ognean, M., Ognean, C. F., \& Darie, N. (2010). Rheological effects of some natural fibers used in breadmaking. Acta Universitatis Cibiniensis Series E: Food Technology, 14(23), 3-10.

27. Pandey K C and Roy A K (2011) Forage Crops Varieties. IGFRI Jhansi (India).

28. Pandey, S., Chaturvedi, N., and Gupta, D. (2019). Effect of Malting on Nutritional Profile of Alfalfa Seeds and Development of Value Added Fermented Products". International Journal of Fermented Foods, 8(2), 73-78.

29. Reddy, C. K., Pramila, S., \& Haripriya, S. (2015). Pasting, textural and thermal properties of resistant starch prepared from potato (Solanum tuberosum) starch using pullulanase enzyme. Journal of food science and technology, 52(3), 1594-1601.

30. Sahni, P., \& Sharma, S. (2020). Influence of processing treatments on cooking quality, functional properties, antinutrients, bioactive potential and mineral profile of alfalfa. $L W T, 132,109890$.

31. Sahni, P., Sharma, S., \& Singh, B. (2021). Impact of different processing treatments on techno and biofunctional characteristics of dhaincha (Sesbania aculeate). Food Science and Technology International, 27(3), 251-263.

32. Sahni, P., Sharma, S., \& Surasani, V. K. R. (2020). Influence of processing and pH on amino acid profile, morphology, electrophoretic pattern, bioactive potential and functional characteristics of alfalfa protein isolates. Food Chemistry, 333, 127503

33. Sahni, P., Sharma, S. and Singh, B. (2019). Evaluation and quality assessment of defatted microalgae meal of Chlorella as an alternative food ingredient in cookies, Nutrition \& Food Science, 49(2), 221-231.

34. Sahni, P., Singh, B., and Sharma, S. (2018). Functionality of proteins and its interventions in food. IFI Mag 37(3), 41-52.

35. Segev, A., Badani, H., Galili, L., Hovav, R., Kapulnik, Y., Shomer, I., et al. (2012). Effects of baking, roasting and frying on total polyphenols and antioxidant activity in colored chickpea seeds. Food and Nutrition Sciences, 3(3), 369-376.

36. Shafie, B., Cheng, S. C., Lee, H. H., \& Yiu, P. H. (2016). Characterization and classification of whole-grain rice based on rapid visco analyzer (RVA) pasting profile. International Food Research Journal, 23(5), 2138-2143.

37. Singh, A., Sharma, S., \& Singh, B. (2017). Influence of grain activation conditions on functional characteristics of brown rice flour. Food Science and Technology International, 23(6), 500-512. 
38. Sofi, S. A., Singh, J., Muzaffar, K., Mir, S. A., \& Dar, B. N. (2020). Effect of germination time on physico-chemical, functional, pasting, rheology and electrophoretic characteristics of chickpea flour. Journal of Food Measurement and Characterization, 14, 2380-2392.

39. Usoltsev, D., Sitnikova, V., Kajava, A., \& Uspenskaya, M. (2019). Systematic FTIR spectroscopy study of the secondary structure changes in human serum albumin under various denaturation conditions. Biomolecules, 9(8), 359.

40. Vizitiu, D., \& Danciu, I. (2011). Evaluation of farinograph and mixolab for prediction of mixing properties of industrial wheat flour. Acta Universitatis Cibiniensis Series E: Food Technology, 15(2), 31-38.

41. Zhong, Y., Xiang, X., Zhao, J., Wang, X., Chen, R., Xu, J., ... \& Liu, C. (2020). Microwave pretreatment promotes the annealing modification of rice starch. Food chemistry, 304, 125432. 